\title{
Matrine inhibits prostate cancer via activation of the unfolded protein response/endoplasmic reticulum stress signaling and reversal of epithelial to mesenchymal transition
}

\author{
JUNLI CHANG ${ }^{1,2 *}$, SHAOPU HU ${ }^{1,2^{*}}$, WENYI WANG ${ }^{1,2}$, YIMIAN LI $^{1,2}$, WENLAN ZHI $^{1,2}$, \\ SHENG LU ${ }^{1,2}$, QI SHI ${ }^{1,2}$, YONGJUN WANG ${ }^{1,2}$ and YANPING YANG ${ }^{1,2}$ \\ ${ }^{1}$ Department Orthopedics and Traumatology, Longhua Hospital, Shanghai University of Traditional Chinese Medicine; \\ ${ }^{2}$ Key Laboratory of Theory and Therapy of Muscles and Bones, Ministry of Education, Shanghai 200032, P.R. China
}

Received January 14, 2018; Accepted May 15, 2018

DOI: $10.3892 / \mathrm{mmr} .2018 .9061$

\begin{abstract}
Prostate cancer is the second most commonly diagnosed malignancy and the sixth global primary cause of malignancy-associated fatality. Increased invasiveness and motility in prostate cancer cells are associated with ubiquitin proteasome system-regulated epithelial to mesenchymal transition (EMT). Impairment of the endoplasmic reticulum (ER) causes ER stress due to the accumulation of unfolded proteins and altered cell survival. In the current study, the effect and mechanism of matrine on cell apoptosis, viability, migration and invasion of human prostate cancer cells in vivo and in vitro through the unfolded protein response (UPR)/ER stress pathway were investigated. Matrine inhibited proteasomal chymotrypsin-like (CT-like) activity in the prostate carcinoma cellular proteasome. Upregulated vimentin and $\mathrm{N}$-cadherin and downregulated E-cadherin were also observed in vitro and in vivo. In vitro analyses showed that matrine repressed cell motility, viability and invasion, arrested the cell cycle at the $\mathrm{G}_{0} / \mathrm{G}_{1}$ phase and induced prostate cancer cell apoptosis. Furthermore, matrine activated the UPR/ER stress signaling cascade in prostate cancer cells and tumor tissues of xenograft-bearing nude mice. Results also demonstrated that the anti-apoptotic protein Bcl-2 was downregulated, the pro-apoptotic protein Bak was upregulated and the cell growth and cell cycle-related proteins c-Myc, Cyclin B1, Cyclin D1 and CDK1 were downregulated. Moreover, matrine inhibited
\end{abstract}

Correspondence to: Professor Yanping Yang, Department Orthopedics and Traumatology, Longhua Hospital, Shanghai University of Traditional Chinese Medicine, 725 S. Wanping Road, Shanghai 200032, P.R. China

E-mail: yanpingyangks@163.com

${ }^{*}$ Contributed equally

Key words: matrine, prostate cancer, xenograft-bearing nude mice, proteasomal chymotrypsin-like activity, epithelial to mesenchymal transition, unfolded protein response/endoplasmic reticulum stress tumor growth and $\mathrm{Ki}-67$ expression in xenograft-bearing nude mice. To the best of our knowledge, the present study indicated for the first time that matrine exerted marked anticancer functions in human prostate carcinoma in vivo and in vitro through activation of the proteasomal CT-like activity inhibition mediated by the UPR/ER stress signaling pathway.

\section{Introduction}

Prostate cancer is the 2 nd most commonly diagnosed malignancy, as well as the 6th principal reason for malignancy associated mortality worldwide $(1,2)$. Thanks to the progress in prostate-specific antigen (PSA) analysis and management, prostate cancer without metastasis is a largely treatable disease. However, existing therapeutics cannot effectively treat metastatic prostate cancer. There were 28,170 prostate cancer patients who died of metastatic disease in 2012, as estimated by the American Cancer Society (3-5). As a hallmark capability of cancer, epithelial to mesenchymal transition (EMT) has become more and more accepted as a key step in promoting cancer cell invasion and metastasis into distant organs (6), which also occurs in human prostate cancer (5).

EMT causes epithelial cells to separate from their neighbors and cross the basement membrane. They then move across the extracellular matrix into different organ sites, or to distant tissues. EMT also provides crucial understanding as to how tumor cells achieve invasive capacity by losing epithelial properties, including E-cadherin, and obtain mesenchymal characteristics, such as vimentin and $\mathrm{N}$-cadherin, to generate resistance against drugs and apoptosis, encourage viability, and promote motility and invasion into adjacent tissues (5,7-9). Thus, it may be possible to regulate the malignant behaviors of prostate cancer cells by reversing EMT, and improving our understanding of the associated signaling pathways is essential to the development of new effective therapies.

Many signal transduction pathways involved in EMT are regulated by the ubiquitin proteasome system (UPS) (10), which maintains the homeostasis of the cell cycle and tumor growth by controlling the degradation of important regulatory proteins (11-13). Proteasomal activity suppression is a promising strategy for reversing tumor cell apoptosis resistance 
and augmenting cancer cell sensitivity against chemotherapy, and is a novel specific exclusive cancer therapeutic strategy (13-16). The $26 \mathrm{~S}$ proteasome is a multi-catalytic enzyme complex with a $20 \mathrm{~S}$ proteolytic core. The $20 \mathrm{~S}$ proteasome particle includes three pairs of proteolytic regions with specific substrates including trypsin-like, peptidyl-glutamyl peptide hydrolyzing (PGPH) and chymotrypsin (CT)-like activities (17-19). Proteasomal CT-like activity is associated with the cell survival of cancer cells $(20,21)$. Therefore, down-regulation of CT-like activity to reverse EMT may be an effective approach for preventing prostate cancer metastasis.

Clinical studies have suggested that proteasome inhibitors are prospective novel anticancer reagents. Matrine (Fig. 1A and B) is a natural product derived from Sophora flavescens, the traditional Chinese herbal medicine that has been shown to reduce the risk of viral hepatitis (22) and atopic dermatitis (23). The anticancer activities of matrine have begun to be clarified recently (24), including in pancreatic cancer and hepatoma $(25,26)$. However, the potential function of matrine in preventing prostate cancer metastasis, and the molecular mechanism, are poorly understood.

Endoplasmic reticulum (ER) stress was found to be involved in cytotoxicity due to proteasomal activity inhibition in cancer cells (27), which was induced by unfolded protein accumulation in the ER, known as the unfolded protein response (UPR). If cell damage is sufficiently severe, UPR/ER stress signaling will induce cell death by apoptosis (28-31). ER stress also can control oncogene-driven cell transformation (32). In mammals, there are three classes of ER stress sensors (PERK, IRE1 $\alpha$ and ATF6), which are inhibited by the ER-specific chaperone BIP (33). PERK activation reduces general protein synthesis by eukaryotic translation initiator factor $2 \alpha$ (eIF2 $\alpha$ ) phosphorylation, which results in selective ATF4 mRNA expression. ATF4 regulates the translation of essential genes related to apoptosis and growth arrest, such as C/EBP-homologous protein (CHOP). Continued ATF4 expression causes apoptosis, possibly by up-regulating pro-apoptotic protein transcription, such as Bax, and down-regulating the anti-apoptotic proteins of the Bcl-2 family, such as Bcl-2 $(30,34,35)$. Therefore, UPR is a promising cancer treatment target because increased ER stress can cause cell death.

The intention of the current study was to explore the anticancer function of matrine in prostate cancer by reversing EMT, as a result of proteasomal CT-like activity inhibition via activation of UPR/ER stress both in vitro and in vivo.

\section{Materials and methods}

Compounds and reagents. Matrine (cat. no. 519-02-8) was bought from the Institute for Drug Control (Shanghai, China) and dissolved in $\mathrm{H}_{2} \mathrm{O}$. Z-Gly-Gly-Leu-AMC (cat. no. BML-ZW8505) was bought from Enzo Life Sciences, Inc., (Farmingsale, NY, USA). Propidium iodide (cat. no. P8080) and FITC Annexin V (cat. no. 556419) were obtained from BD Biosciences (Franklin Lakes, NJ, USA). RIPA total protein lysis buffer (P0013B), rabbit anti-Ki-67 monoclonal antibody (cat. no. AF1738), and secondary antibodies of goat anti mouse-HRP (cat. no. A0216) and rabbit-HRP (cat. no. A0208) were bought from Beyotime Institute of Biotechnology (JiangSu, China). Antibodies against ubiquitin (P4D1; cat. no. 3936c), Bip (C50B12; cat. no. 3177), Phospho-eIF2 $\alpha$ (Ser51) (D9G8; cat. no. 3398), eIF2 $\alpha$ (D7D3; cat. no. 5324), vimentin (5G3F10; cat. no. 3390), Bak (D4E4; cat. no. 12105), Bcl-2 (cat. no. 2876), c-Myc (D84C12; cat. no. 5605), Cyclin B1 (D5C10; cat. no. 12231), Cyclin D1 (92G2; cat. no. 2978) and CDK1 (POH1; cat. no. 9116) were from Cell Signaling Technology, Inc. (Danvers, MA, USA). The cell cycle detection kit was obtained from Key GENBioTECH (Nanjing, China). Antibodies against E-cadherin (cat. no. 13-1700) and N-cadherin (cat. no. 33-3900) were from Invitrogen (Thermo Fisher Scientific, Inc., Waltham, MA, USA). Antibodies against CREB-2 (ATF4; cat. no. sc-390063) and GADD 153 (CHOP; cat. no. sc-575) were from Santa Cruz Biotechnology, Inc. (Dallas, TX, USA). Antibodies against $\beta$-actin (Cat. no. sc-575) and 4-phenylbutyric acid (PBA; cat. no. P21005) were from Sigma-Aldrich (Merck KGaA, Darmstadt, Germany). SuperSignal Chemiluminescent HRP substrate (cat. no. 34077) was obtained from Thermo Fisher Scientific Inc. TRIzol reagent (cat. no. 15596) was from Invitrogen; Thermo Fisher Scientific, Inc. SYBR Premix Ex Taq II (cat. no. RR420L) and the PrimeScript RT reagent kit (cat. no. RR037A) were from Takara Biotechnology Co., Ltd. (Dalian, China). The TUNEL detection kit (cat. no. KGA7051) was obtained from Key GENBioTECH.

Cell lines and cell culture. Human prostate cancer cells DU 145 and PC-3 were purchased from the American Type Culture Collection (ATCC, Manassas, VA, USA). DU 145 and PC-3 cells were cultured in F12 medium, purchased from Gibco; Thermo Fisher Scientific, Inc., containing streptomycin $(100 \mu \mathrm{g} / \mathrm{ml})$ and penicillin $(100 \mathrm{U} / \mathrm{ml})$, at $37^{\circ} \mathrm{C}$ with $5 \% \mathrm{CO}_{2}$.

Proteasomal CT-like activity assay in cultured living prostate cancer cells. To assess the inhibitory function of matrine on proteasomal CT-like activity in prostate cancer cells, DU 145 or PC-3 prostate cancer cells were seeded $\left(4 \times 10^{4}\right.$ cells/well $)$ in 24-well cell culture plates at $37^{\circ} \mathrm{C}$ in a $5 \% \mathrm{CO}_{2}$ atmosphere for $24 \mathrm{~h}$. Cells were starved for $12 \mathrm{~h}$ in serum-free medium and incubated with different doses of matrine for 0-36 h, and then cultured for an additional $2 \mathrm{~h}$ with $20 \mu \mathrm{M}$ fluorogenic Z-Gly-Gly-Leu-AMC substrate to determine the proteasomal CT-like activity. Cell medium (100 $\mu 1 /$ sample) was then collected for the measurement of free AMCs with a Varioskan Flash Spectral Scanning Multimode Reader using an $380 \mathrm{~nm}$ excitation filter and $460 \mathrm{~nm}$ emission (Thermo Fisher Scientific, Inc.), as described previously (36).

Western blot assay. Total protein was isolated from prostate cancer cells treated with $4 \mathrm{mM}$ matrine for different times, with or without pretreatment with PBA. To examine the protein expression levels, proteins were isolated via SDS-PAGE and transferred onto PVDF membranes, blotted using different antibodies and checked using Super Signal West Matrineco Chemiluminescent Substrate, as described previously (36).

Flow cytometric analysis. To determine the function of matrine on the cell cycle and apoptosis, DU 145 or PC-3 prostate cancer cells were exposed to matrine at the indicated dose and time. The cell cycle was evaluated using the Cell Cycle Detection kit according to the manufacturer's instructions, as 
A

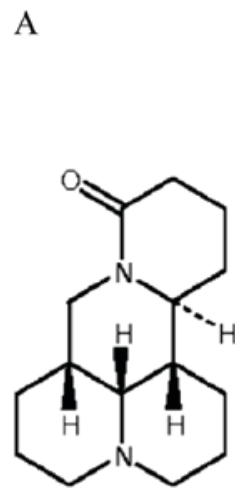

B

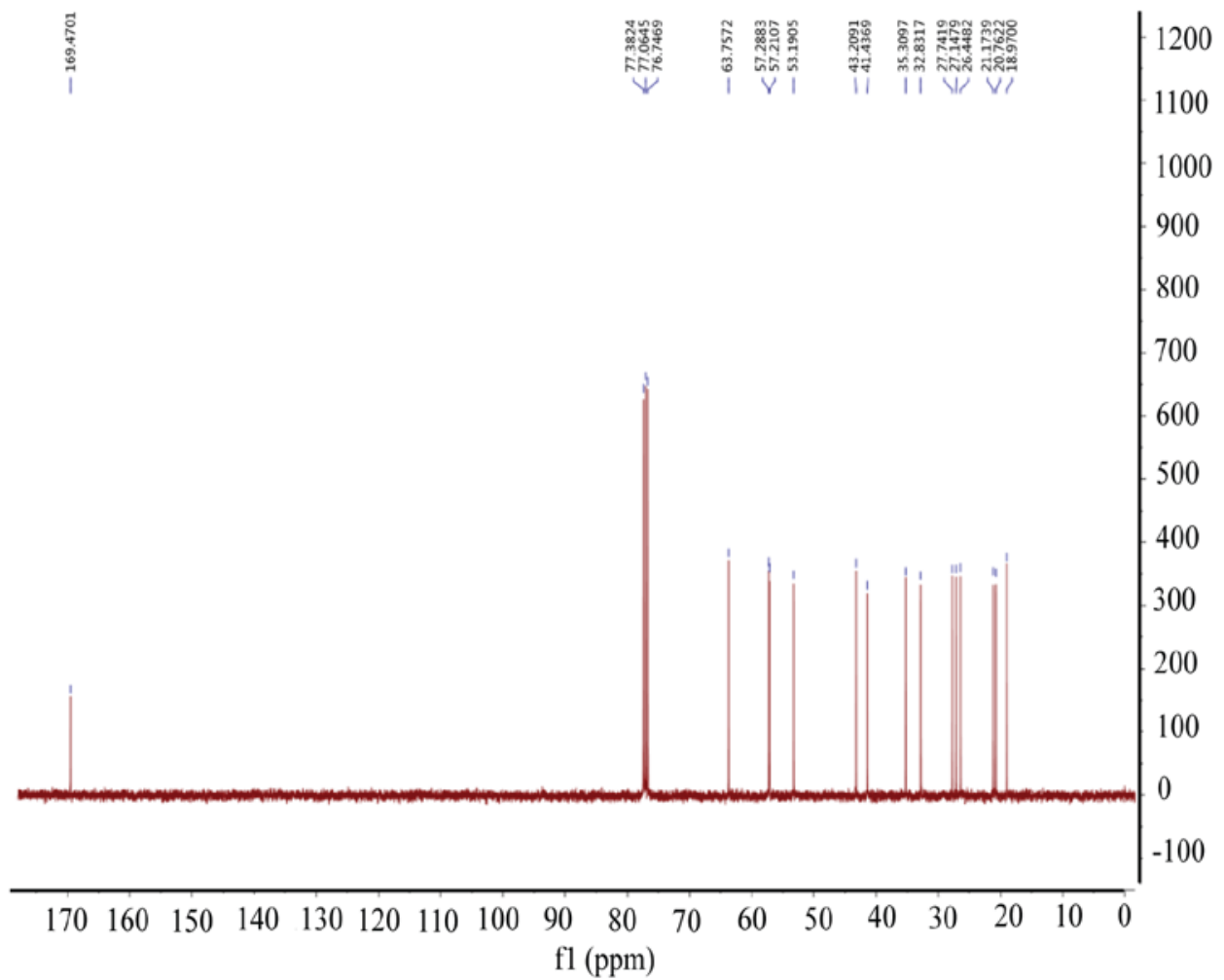

200

100

00

00

$-100$ $\mathrm{fl}(\mathrm{ppm})$

Figure 1. Chemical structure and NMR spectrum of matrine. (A) Chemical structure of matrine; (B) NMR spectrum of matrine.

described previously (36). Briefly, cells to be tested were fixed overnight using cold $70 \%$ ethanol and washed using cold PBS, then incubated with $40 \mu \mathrm{l}$ RNaseA for $30 \mathrm{~min}$ at $37^{\circ} \mathrm{C}$, with $160 \mu \mathrm{l}$ propidium iodide in a dark room at $4^{\circ} \mathrm{C}$ for an additional $30 \mathrm{~min}$. Cells were then measured using a flow cytometer (Accuri C6; BD Biosciences, Franklin Lakes, NJ, USA). The distribution of the cell cycle is represented as the cell percentages of $G_{0} / G_{1}, S$ and $G_{2} / M$. The percentage of apoptotic cells was also determined by flow cytometry after staining with $5 \mu \mathrm{l}$ FITC-labeled Annexin V (BD Pharmingen; BD Biosciences) for $30 \mathrm{~min}$ at room temperature, followed by $5 \mu \mathrm{l}$ propidium iodide $(50 \mu \mathrm{g} / \mathrm{ml})$ (BD Pharmingen; BD Biosciences) on ice for $5 \mathrm{~min}$ in a dark room (36).

Terminal deoxynucleotidyl transferase-mediated dUTP nick end labeling (TUNEL) assay. Briefly, 143B cells were seeded in chamber slides at a density of $1 \times 10^{5}$ cells $/ \mathrm{ml}$, incubated for $24 \mathrm{~h}$, and then treated with PBS or matrine $(2,4,8 \mathrm{mM})$ for $24 \mathrm{~h}$. Cells were fixed in $10 \%$ buffered formalin for $25 \mathrm{~min}$ at room temperature, washed twice with PBS for 5 min and permeabilized by immersing the slides in $0.2 \%$ Triton X-100 solution for $5 \mathrm{~min}$. Subsequently, cells were washed twice with PBS for $5 \mathrm{~min}$. The TdT enzyme reaction mix was added to the slides and incubated at $37^{\circ} \mathrm{C}$ for $60 \mathrm{~min}$, washed twice with PBS for $5 \mathrm{~min}$. The streptavidin-FITC was added to the slides and incubated $30 \mathrm{~min}$. Finally, 4,6-diamidino-2-phenylindole (DAPI) was added to stain the nucleus, and the apoptotic cells were detected by fluorescence microscopy (DM4000B; Leica Microsystems GmbH, Wetzlar, Germany).

Cell viability assay. Prostate cancer cells were harvested after culturing with different doses of matrine for $48 \mathrm{~h}$. Cell viability was detected using a Countstar automated cell counter by loading $20 \mu \mathrm{l}$ cell suspension containing trypan blue $(0.1 \%)$, as described previously (36).

In vitro motility and invasion assay. The migration of human prostate cancer cells was measured using an xCELLigence RTCA DP system, as described previously (36). Briefly, $165 \mu \mathrm{l}$ medium with $10 \%$ FBS was added into the lower chamber and $40 \mu \mathrm{l}$ medium without FBS was added into the upper chamber in each well of the CIM-Plate $16.100 \mu \mathrm{l}$ cell suspension containing 40,000 cells and different concentrations of matrine $(0,2,4$, or $8 \mathrm{mM})$ was added into each upper chamber with a total volume of $140 \mu \mathrm{l}$ medium. Cell migration was then monitored continuously for $24 \mathrm{~h}$. Cell invasion was monitored continuously for $48 \mathrm{~h}$ using the same conditions as the migration assay, except for the upper chambers being pre-coated with Matrigel (1:40 dilution).

Xenograft of prostate cancer in nude mice. Male BALB/c nude mice (6 weeks) were obtained from Shanghai Slac Laboratory Animal Co. (Shanghai, China). All the animal experiments, such as in vivo model preparation and intervention, resection of xenograft cancer tissues to measure tumor volume and tumor weight, and immunohistochemistry analysis, were performed according to protocols approved by the Institutional Animal Care and Use Committee of Shanghai University of TCM (no. SZY2016004).

DU 145 cells $\left(2 \times 10^{6}\right.$ cells $\left./ 100 \mu 1\right)$ were resuspended with sterile physiological saline and inoculated into the right flank of the mice subcutaneously, then the mice were divided at random into 2 groups with 7 mice in each group. On the second day after inoculation, the animals started daily 
intraperitoneal injections of: i) $100 \mu \mathrm{l}$ saline in the control group; or ii) $50 \mathrm{mg} / \mathrm{kg} / \mathrm{day}$ matrine dissolved in saline for the matrine group. The diameters of the tumors were estimated weekly using vernier calipers. To calculate the tumor volumes, the following principle was used: $0.5 \mathrm{x}$ a x b (where $a$ is the largest dimension and the $b$ is square of the smallest diameter). The body weight of the mice was monitored every 3 days. Mice were euthanized after 4 weeks' administration of matrine or saline to dissect the tumor xenografts immediately for weighing, storing and fixing. The following formula was used to calculate the inhibition rate of tumor growth: (Tumor weight of saline treated group-tumor weight of matrine treated group)/tumor weight of saline treated group $\times 100 \%$.

Quantitative analysis of $m R N A$ levels. Total RNA was purified from the xenograft tumors using TRIzol reagent. Primers for Bip were 5'-CCCGTGGCATAAACCCAGAT-3' (forward), 5'-TGGTAGGCACCACTGTGTTC-3' (reverse); ATF-4 were 5'-TTAAGCCATGGCGCTTCTCA-3' (forward), 5'-TCCTTGCTGTTGTTGGAGGG-3' (reverse); PARP were 5'-TTCAACAAGCAGCAAGTGCC-3' (forward), 5'-CCT TTGGGGTTACCCACTCC-3' (reverse); Bcl-2 were 5'-GGT GAACTGGGGGAGGATTG-3' (forward), 5'-ATCACCAAG TGCACCTACCC-3' (reverse); Cyclin B1 were 5'-TCTGCT GGGTGTAGGTCCTT-3' (forward), 5'-ACCAATGTCCCC AAGAGCTG-3' (reverse); vimentin were 5'-GGACCAGCT AACCAACGACA-3' (forward), 5'-AAGGTCAAGACG TGCCAGAG-3' (reverse) and GAPDH were 5'-TGTTGC CATCAATGACCCCTT-3' (forward), 5'-CTCCACGACGTA CTCAGCG-3' (reverse). Reverse transcriptional PCR was performed with the PrimeScript RT reagent kit. RT-PCR was performed using SYBR Premix Ex Taq II in the Bio-Rad CFX 96 (Bio-Rad Laboratories, Inc., Hercules, CA, USA) qPCR system. GAPDH was used as the internal control, and $2^{-\Delta \Delta C q}$ was used to calculate the fold changes. Each experiment was conducted in triplicate.

Immunohistochemical analyses. Xenograft tumor tissues, fixed in $10 \%$ neutral buffered paraformaldehyde for $24 \mathrm{~h}$ at $4^{\circ} \mathrm{C}$, were randomly selected, embedded in paraffin, sliced $(5-\mu \mathrm{m}$ thick), deparaffinized and rehydrated with PBS, and treated in $3 \% \mathrm{H}_{2} \mathrm{O}_{2}$ for $10 \mathrm{~min}$. Antigen retrieval was performed at $37^{\circ} \mathrm{C}$ for $10 \mathrm{~min}$ with $0.1 \%$ trypsin $(\mathrm{M} / \mathrm{V})$. The slices were stained with the indicated primary antibodies at $4^{\circ} \mathrm{C}$ overnight after $5 \%$ BSA blocking, followed by culture with the secondary antibody. Slides were counterstained with hematoxylin after 5 min of staining with DAB, and then mounted using neutral gum after permeabilizing using xylene. An image autoanalysis system (Olympus BX50; Olympus Corporation, Tokyo, Japan) was used to acquire images, and a representative image is presented. Positive expression was indicated by strong brown staining.

Statistical analysis. Representative data from triplicate experiments are presented. To compare data from multiple groups, one-way ANOVA followed by the Tukey-Kramer or Holm-Sidak tests was used. To compare data from two groups, a Student's t-test was used. $\mathrm{P}<0.05$ was considered to indicate a statistically significant difference.

\section{Results}

Matrine inhibited the cellular proteasomal CT-like activity of prostate cancer cells. Proteasomal CT-like activity is related to cancer cell viability. Previous reports suggest that Chinese herbal medicines with proteasome inhibitor activities mostly have antipyretic-antioxidant effects. Matrine is an ethanol extract from Sophora flavescens, a traditional Chinese herbal medicine with antipyretic and antioxidant functions. We hypothesized that matrine could potentially inhibit proteasomal activity and result in the inhibition of prostate cancer. Thus, we investigated whether matrine would reduce the proteasomal CT-like activity of prostate cancer cells. It was revealed that matrine significantly inhibited the proteasomal CT-like activity of both PC-3 and DU145 prostate cancer cells in a concentration dependent (Fig. 2A) and time dependent manner (Fig. 2B). Meanwhile, both DU145 and PC-3 prostate cancer cells showed a time-dependent accumulation of ubiquitinated proteins (Ub-Prs) with $4 \mathrm{mM}$ matrine treatment (Fig. 2C).

Matrine reversed EMT and inhibited the viability of prostate cancer cells. Prostate cancer cells showed EMT with characteristic changes in vimentin, $\mathrm{N}$-cadherin and $\mathrm{E}$-cadherin expression. Therefore, we proposed to investigate the function of matrine in reversing EMT by measuring mesenchymal and epithelial markers. The results showed that challenge with matrine led to up-regulation of the epithelial marker E-cadherin, and down-regulation of the mesenchymal markers vimentin and $\mathrm{N}$-cadherin (Fig. 3A).

Taken together, our results indicate that, in vitro, matrine negatively regulates EMT in prostate cancer cells.

EMT-like status is also related to an increase in cell viability under diverse conditions, including therapeutic resistance. Thus, we further assessed the potential antitumor effects of matrine on prostate cancer cells by detecting the viability of prostate cancer cells. As assessed using the Countstar automated cell counter, prostate cancer cells challenged with 2 , 4 or $8 \mathrm{mM}$ matrine for $72 \mathrm{~h}$ exhibited an inhibition of cell growth, which was dose-dependent in DU145 (Fig. 3B, left panel) and PC-3 (Fig. 3B, right panel). To further investigate in more detail, we conducted apoptosis and cell cycle assays in DU145 and PC-3 cells challenged with 2, 4 or $8 \mathrm{mM}$ matrine for $24 \mathrm{~h}$. Flow cytometric analysis was used to detect the cell cycle distribution after propidium iodide staining. As shown in Fig. $3 \mathrm{C}$, prostate cancer cells were arrested at the $\mathrm{G}_{0} / \mathrm{G}_{1}$ phase. Furthermore, the higher the concentration of matrine used, the greater the number of DU145 (Fig. 3C, left panel) and PC-3 (Fig. 3C, right panel) cells blocked at the $\mathrm{G}_{0} / \mathrm{G}_{1}$ phase. Cell death was estimated by examining the apoptotic percentage. As presented in Fig. 3D, flow cytometric analysis was used to determine the percentage of apoptotic cells with FITC-labeled Annexin- $\mathrm{V}$ and propidium iodide staining. Early apoptotic (only stained with Annexin V-FITC) and late apoptotic (double stained with propidium iodide and Annexin V-FITC) percentages were pooled for analysis. Matrine dose-dependently caused increased apoptosis in both DU145 (Fig. 3D, left panel) and PC-3 (Fig. 3D, right panel) cells, the apoptosis in DU145 cells was further confirmed by TUNEL assay (Fig. 3E). These data suggested that matrine could exert a significant growth inhibitory effect on prostate cancer cells. 

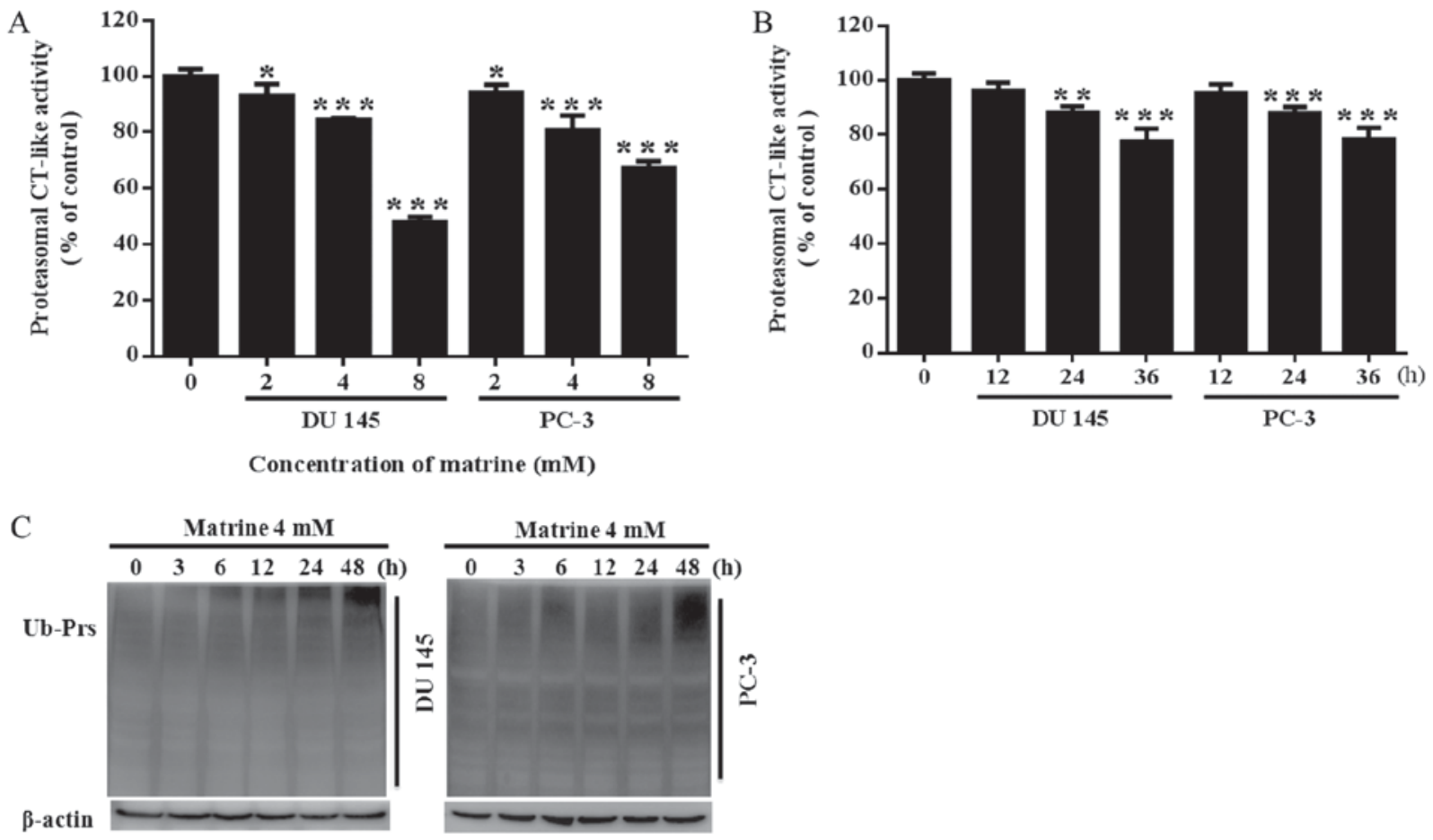

Figure 2. Inhibitory effects of matrine on chymotrypsin-like activity in prostate cancer cells. (A) Concentration-dependent effects of matrine on DU 145 or PC-3 prostate cancer cells. DU 145 or PC-3 cells were treated with $0,2,4$ or $8 \mathrm{mM}$ matrine for $36 \mathrm{~h}$, followed by measuring the inhibitory effect of the proteasomal CT-like activity using Z-Gly-Gly-Leu-AMC. (B) Time-effects of matrine on DU 145 or PC-3 prostate cancer cells. DU 145 or PC-3 cells were treated with $4 \mathrm{mM}$ matrine for the indicated times, followed by measuring the inhibitory effect of the proteasomal CT-like activity using Z-Gly-Gly-Leu-AMC. (C) The accumulation of Ub-Prs in DU 145 or PC-3 prostate cancer cells exposed to matrine $(4 \mathrm{mM})$ for 0-48 h was determined by western blotting. Representative data are shown from independent triplicate experiments with similar results. ${ }^{*} \mathrm{P}<0.05,{ }^{* *} \mathrm{P}<0.01,{ }^{* * * *} \mathrm{P}<0.001$ vs. the control. CT-like, chymotrypsin-like.

Matrine decreased the migration and invasion of prostate cancer cells. The exchange of cadherin is a characteristic EMT-like transformation which assists adhesion among homotypic cells and is generally associated with invasion and migration, the key processes for encouraging metastatic dissemination (37). To explore the functions of matrine in reversing invasion and migration, the xCELLigence RTCA DP system was used in DU145 cells. It was revealed that matrine treatment significantly inhibited the capacity of DU145 cell migration (Fig. 3F), invasion (Fig. 3G) and induced the morphological changes (Fig. 3H) in a concentration- and time-dependent manner compared with those cells without matrine treatment.

Matrine activated the UPR/ER stress signaling cascade and regulated the target genes involved in human prostate cancer cell apoptosis and the cell cycle. The proteasome controls the degradation of misfolded proteins. Proteasome inhibitors may increase unfolded protein accumulation, leading to enhanced ER stress due to UPR. The Bcl-2 family and CHOP are the major mediators of ER stress-dependent apoptosis (29). Therefore, targeting factors associated with UPR-induced ER stress is a possible approach for the management of malignancy. 4-phenylbutyric acid (PBA) is a small-molecule chemical chaperone that stabilizes the conformation of proteins and improves the folding ability of proteins in the ER, as well as facilitating mutant protein trafficking, while ER stress can be attenuated by PBA $(38,39)$.

To further understand the molecular mechanism related to matrine-stimulated changes in prostate cancer cell survival and proteasomal activity inhibition. The key components of the UPR/ER stress signaling pathway, and the target genes associated with apoptosis and the cell cycle were investigated using western blotting. We found that both DU145 and PC-3 prostate cancer cells exposed to $4 \mathrm{mM}$ of matrine exhibited time-dependent activation of the PERK branch in UPR, as evidenced by increased BiP expression, improved eIF2 $\alpha$ phosphorylation, and up-regulated GADD153 (CHOP) and ATF4 (Fig. 4A). By detecting the associated target genes, we further found that matrine inhibited anti-apoptotic protein expression, such as Bcl-2, while increasing pro-apoptotic protein expression, such as Bax (Fig. 4B). DU145 and PC-3 cells exposed to matrine $(4 \mathrm{mM})$ also exhibited time-dependent inhibition of the expression of Cyclin D1, Cyclin B1, c-Myc and CDK1 (Fig. 4C), indicating that matrine break down the complex of Cyclin/CDK1, which is important for continuously reshuffling core elements following transition between cell cycle phases after rapid division of cells (40), and resulted in $\mathrm{G}_{0} / \mathrm{G}_{1}$ phase arrest in the prostate cancer cell cycle (Fig. 3C). Meanwhile, the activated UPR/ER stress signaling cascade (Fig. 4D) in prostate cancer cells caused by matrine was attenuated by pretreatment of the DU 145 and PC-3 human prostate cancer cells with PBA $(40 \mu \mathrm{M})$ for $24 \mathrm{~h}$ before challenge with matrine.

Altogether, these data implied that matrine provoked apoptosis and inhibited cell proliferation in DU 145 and PC-3 prostate cancer cells via specific up-regulation of UPR leading to the activation of ER stress.

Matrine has therapeutic efficacy for prostate cancer xenografts associated with activation of UPR/ER stress signaling, thus reversing EMT, and inducing apoptosis and cell cycle 

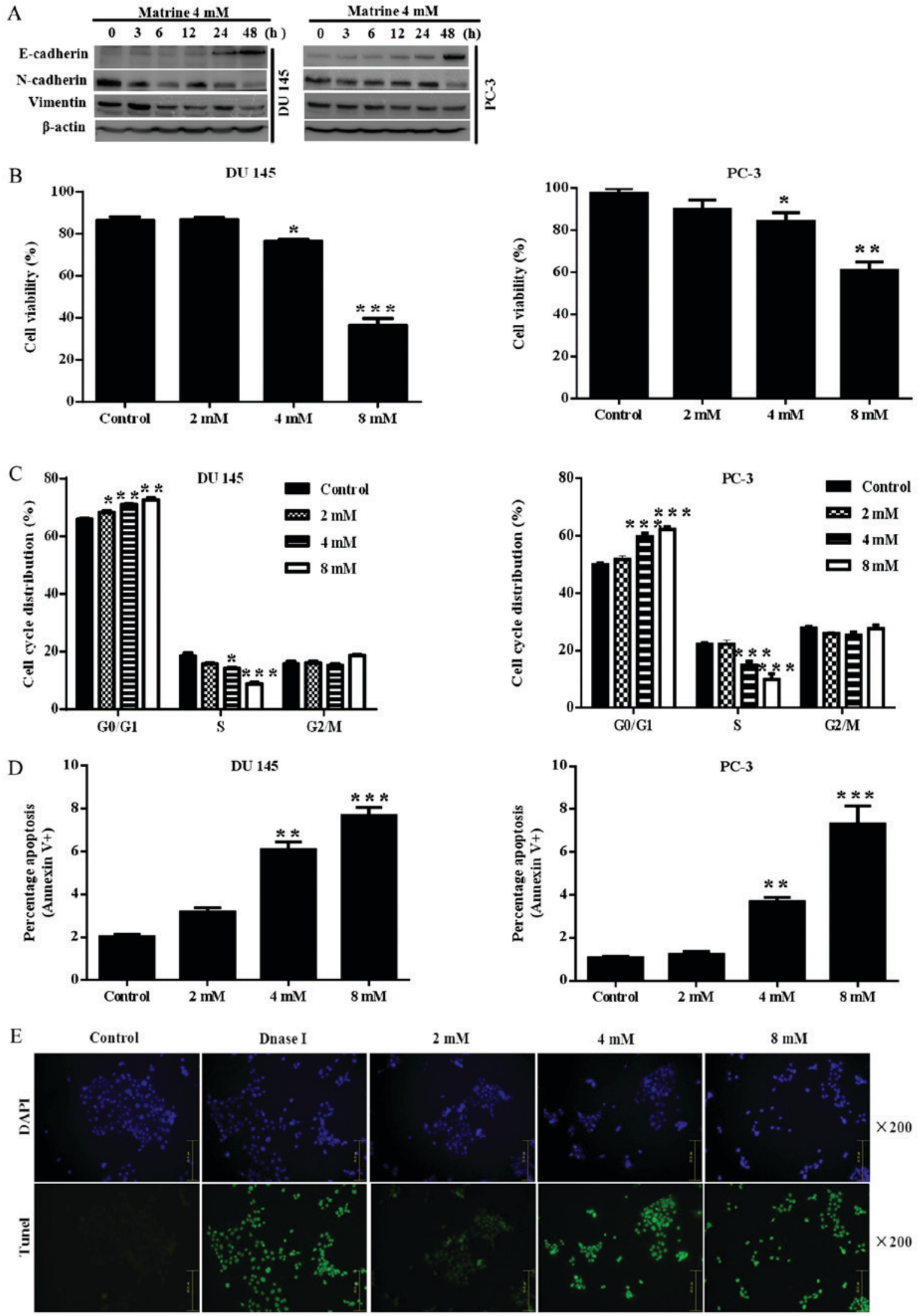

Figure 3. Matrine inhibited EMT in human prostate cancer cells and the related cell activities. (A) Western blotting revealed that exposure to matrine resulted in increased expression of E-cadherin, and reduced expression of N-cadherin and Vimentin in DU 145 or PC-3 prostate cancer cells. $\beta$-actin was used as a loading control. The data above are representative of three experiments with similar results. (B) The viability of DU 145 and PC-3 prostate cancer cells after exposure to matrine (0-4 mM) for $48 \mathrm{~h}$, which was calculated using a Countstar automated cell counter. (C) The percentage distribution of the prostate cancer cell cycle. After treatment for $24 \mathrm{~h}$, effects of matrine at $0-8 \mathrm{mM}$ on the cell cycle of DU 145 and PC-3 prostate cancer cells were determined. (D and E) The apoptosis of prostate cancer cells. Apoptotic cells were determined in DU 145 and PC-3 prostate cancer cells by flow cytometry and/or TUNEL assay, after exposure to different concentrations of matrine for $24 \mathrm{~h}$. Images of TUNEL assay (E) were obtained using an LEICA DMI3000B microscope (magnification, $\mathrm{x} 200)$. 
$\mathrm{F}$

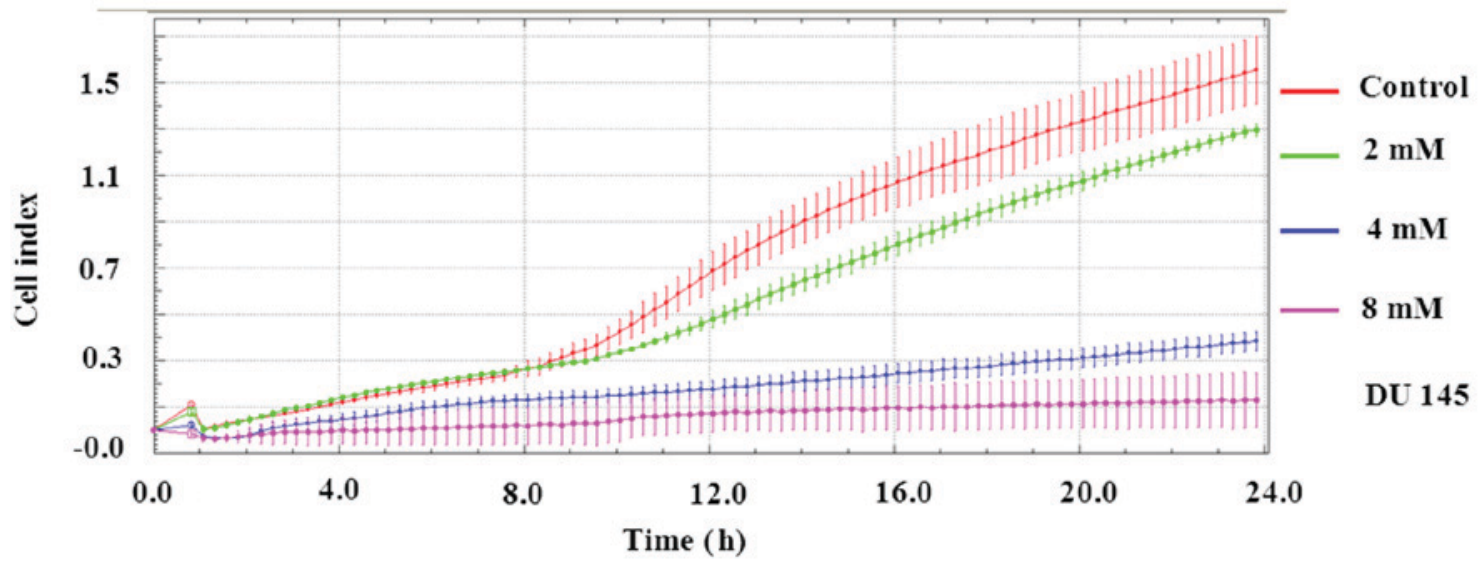

G

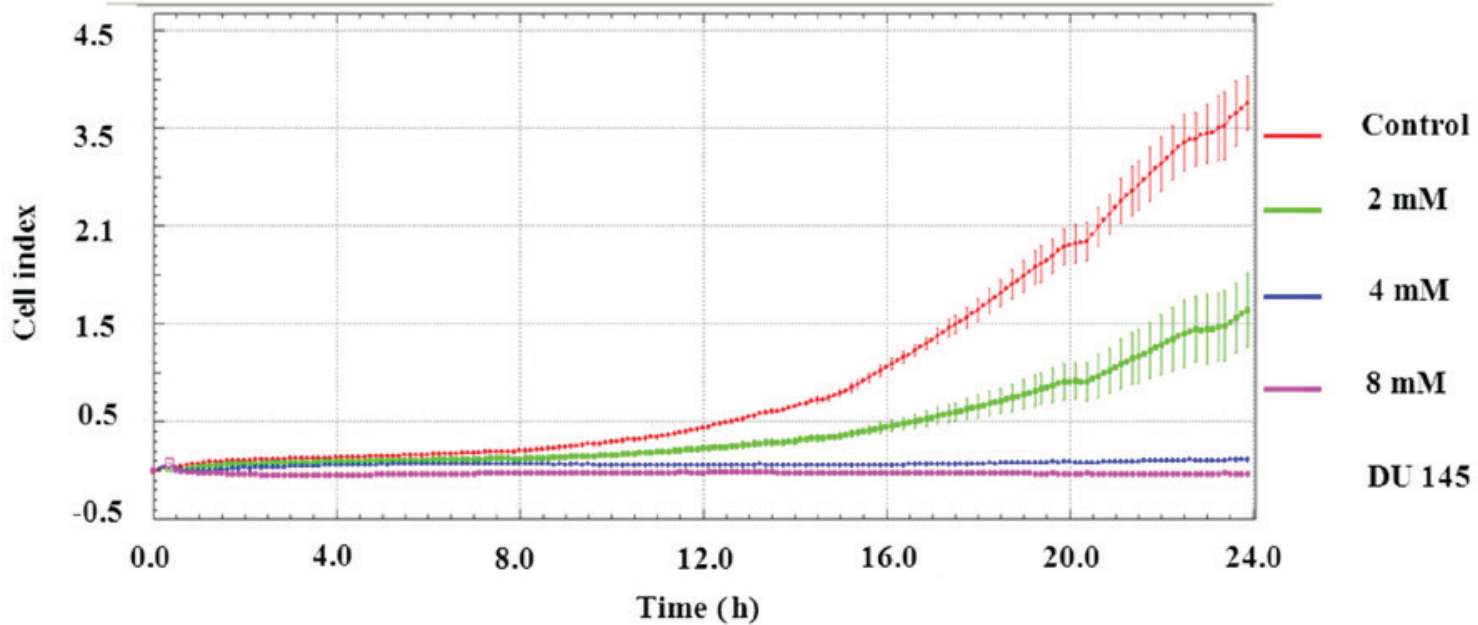

$\mathrm{H}$
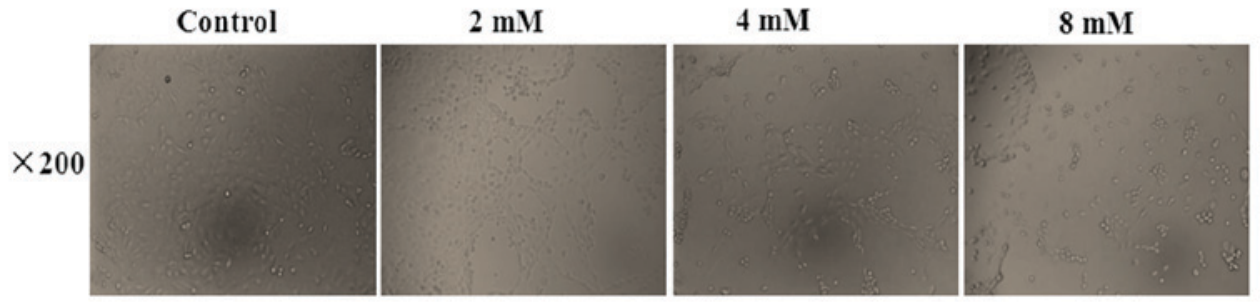

Figure 3. Continued. (F) Matrine inhibited cell migration in human prostate cancer DU 145 cells. (G) Matrine decreased cell invasion in human prostate cancer DU 145 cells. Representative data are shown from three independent experiments with similar results. (H) Matrine induced morphological change of human prostate cancer DU 145 cells demonstrating the EMT. Images were obtained using an LEICA DMI3000B microscope (magnification, $\mathrm{x} 200)$. ${ }^{*} \mathrm{P}<0.05,{ }^{* *} \mathrm{P}<0.01$, ${ }^{* * * *} \mathrm{P}<0.001$ vs. the control. EMT, epithelial to mesenchymal transition.

arrest in vivo. The data mentioned above clearly showed that matrine could inhibit prostate cancer cell viability by inhibiting proteasomal activity and UPR/ER stress signaling activation-associated reversal of EMT, inducing apoptosis and cell cycle arrest. To explore whether matrine had the same therapeutic function and mechanism in prostate cancer in vivo, prostate cancer DU 145 cells were subcutaneously inoculated into the right flank of each mouse. The results showed that matrine significantly suppressed tumor growth in vivo, as evidenced by tumor volume (Fig. 5A) and tumor weight (Fig. 5B); the tumor growth inhibition rate with matrine treatment was $49.77 \%$ relative to control mice treated with the saline. Matrine caused no obvious toxic effects on mice at a dose of $50 \mathrm{mg} / \mathrm{kg} / \mathrm{day}$, and the body weights were not changed in the matrine treatment group vs. the saline treatment group (Fig. 5C).
The in vitro data showed that matrine was a potential natural proteasome inhibitor and caused Ub-Prs accumulation in prostate cancer cells. To explore whether matrine could also reduce proteasomal activity, and therefore stimulate Ub-Prs accumulation in prostate cancer xenografts, the expression of Ub-Prs in DU 145 xenografts was detected by immunohistochemistry staining. A significant up-regulation in Ub-Prs was observed in the prostate cancer xenografts after matrine treatment vs. the saline treatment (Fig. 6A), indicating that matrine also induced Ub-Prs accumulation in prostate cancer xenografts; thus, intraperitoneal injections of matrine can inhibit the proteasome in prostate tumors in vivo.

The constitutive activation of UPR/ER stress signaling after treatment with matrine was further confirmed in vivo by increased BiP and ATF4 expression, both at the protein 

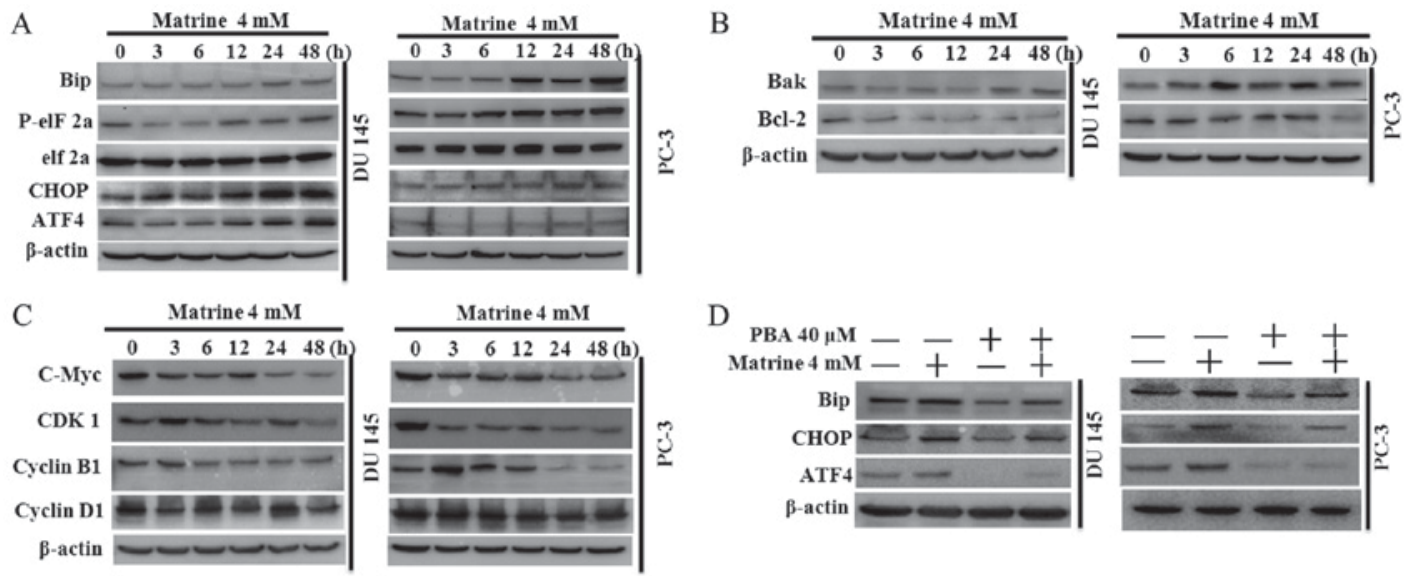

Figure 4. Matrine suppressed human prostate cancer cells by specifically activating the ER stress/UPR signaling pathway. The expression of key components of the PERK branch in the ER stress/UPR signaling pathway: (A) main target genes of ER stress/UPR mediating apoptosis; (B) the cell growth and (C) cell cycle, after DU 145 and PC-3 human prostate cancer cells were exposed to $4 \mathrm{mM}$ matrine for 0-48 h; (D) the specific small-molecule chemical chaperone PBA could attenuate matrine-induced activation of the UPR/ER stress signaling pathway in human prostate cancer cells. The DU 145 and PC-3 prostate cancer cells were pretreated with PBA for $24 \mathrm{~h}$ before exposure to $4 \mathrm{mM}$ matrine for another $24 \mathrm{~h}$. Total proteins were extracted and western blotting was performed. $\beta$-Actin was used as a loading control. The data above are representative of three experiments with similar results. ER, endoplasmic reticulum; UPR, unfolded protein response; PBA, 4-phenylbutyric acid.
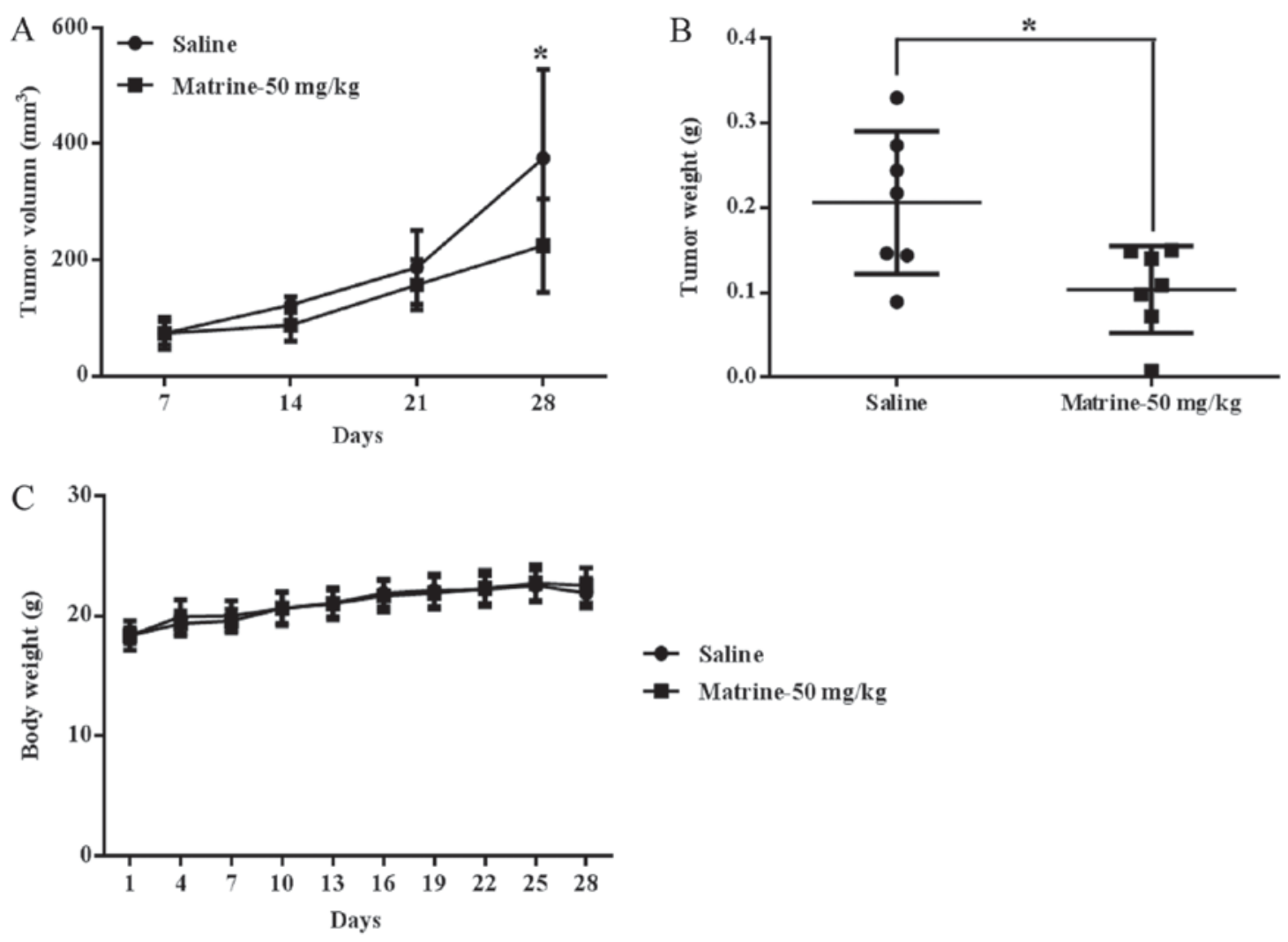

Figure 5. Matrine suppressed localized growth of DU 145 cells in xenograft-bearing nude mice. DU 145 cells were inoculated subcutaneously into the right flank of each nude mouse, which were intraperitoneally dosed daily with matrine $(50 \mathrm{mg} / \mathrm{kg} / 100 \mu \mathrm{l}$ ) or an equal volume of saline for 4 weeks. (A) Tumor volume was measured (mean $\pm \mathrm{SD} ; \mathrm{n}=7{ }^{*}{ }^{*} \mathrm{P}<0.05$; vs. the saline treatment). (B) The tumor weights of mice treated with the saline or matrine. (C) Changes in body weight between matrine- and saline-treated groups. The tumor growth inhibitory rate caused by matrine $(50 \mathrm{mg} / \mathrm{kg}) \mathrm{was} 49.77 \%$.

(Fig. 6B and C) and mRNA (Fig. 6I and J) levels, in the tissues from matrine treated vs. saline treated prostate tumors. Molecular changes associated with the reversal of EMT were also determined in the tumor tissues from prostate cancer xenografts, which showed significantly up-regulated E-cadherin (Fig. 6D) and down-regulated Vimentin (Fig. 6E and K), indicating that matrine decreases the in vivo metastasis of prostate carcinoma by reversing EMT.

To further define the in vivo mechanism of tumor growth inhibition, the expression of Ki-67 in xenograft tumor tissues was identified by immunohistochemistry staining (Fig. 6F); it was shown that matrine significantly decreased 
A

Ub-Prs expression in tumors

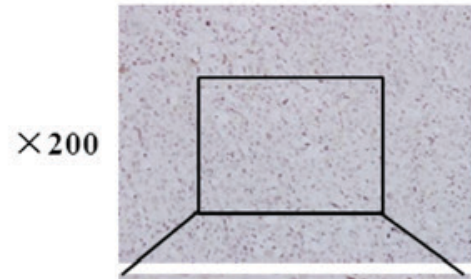

$\times 400$

Sal

C

$\times 200$

$\times 400$

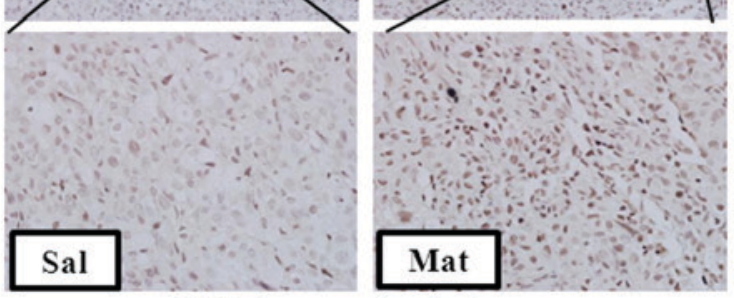

ATF-4 expression in tumors

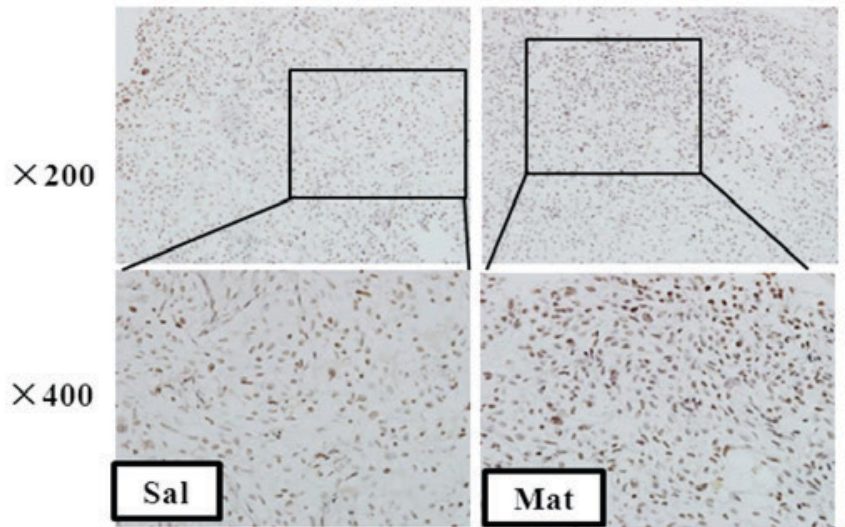

$\mathrm{E}$

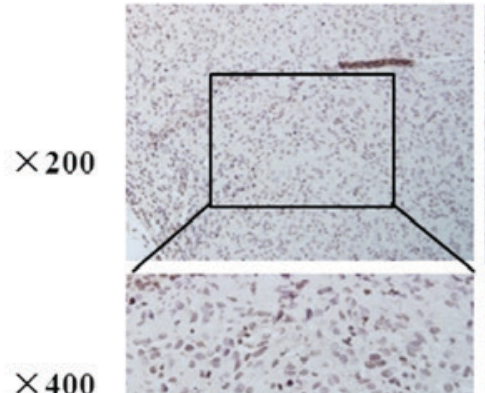

$\times 400$

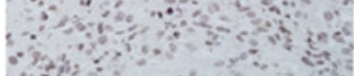

\section{Sal}

G

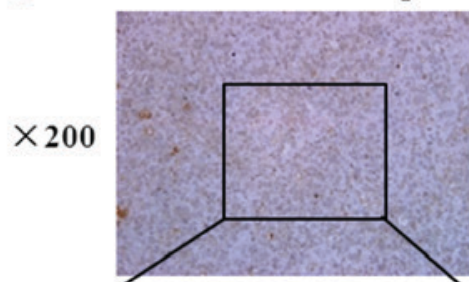

$\times 400$
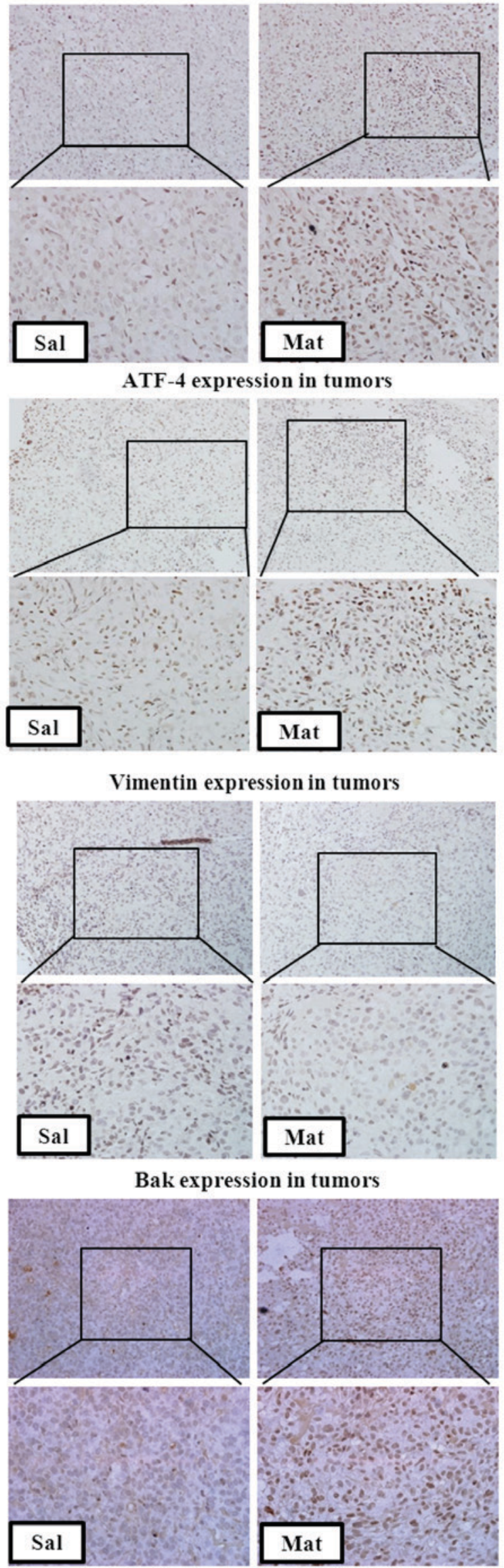

D

$\times 400$

$\mathrm{H}$
B

$\times 200$

$\times 400$

Sal

E-cadherin expression in tumors

$\times 200$

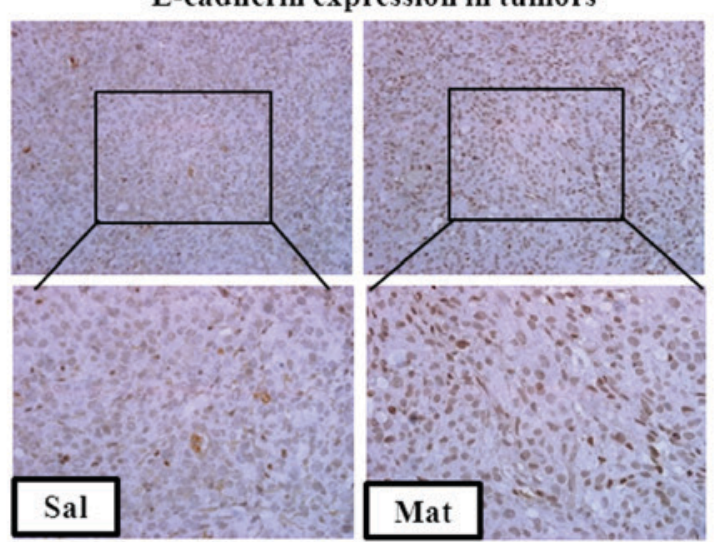

F

$\times 200$

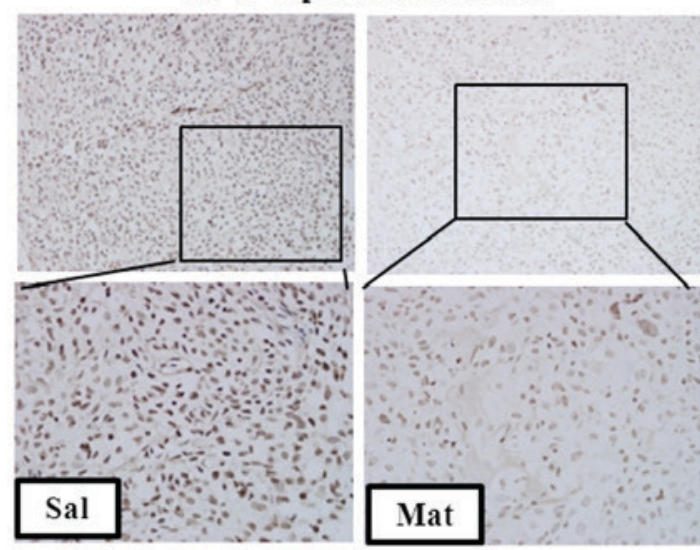

Bip expression in tumors

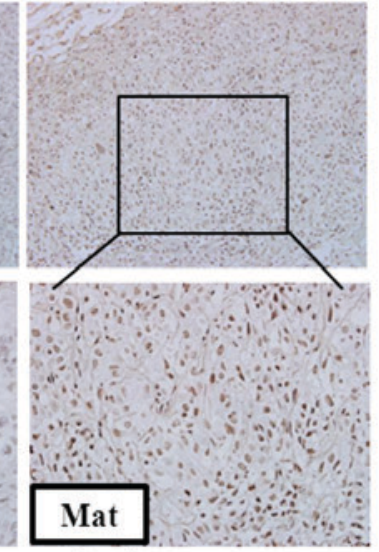

Ki-67 expressionin tumors

PARP expression in tumors

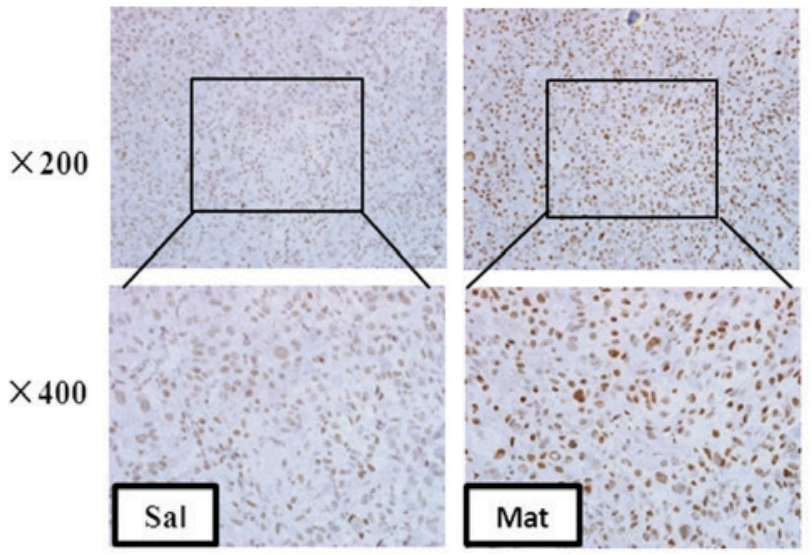

Figure 6. Immunohistochemistry and RT-qPCR analysis of ER stress/UPR signaling cascade proteins and target genes involved in apoptosis and the cell cycle in tumor tissues. Immunohistochemistry staining of paraffin-embedded 5-micron thick tumor sections of xenograft-bearing mice. The expression of (A) accumulated Ub-Prs; (B) Bip; (C) ATF-4; (D) E-cadherin; (E) Vimentin; (F) Ki-67; (G) Bak; and (H) PARP. Original magnification, 200x. 

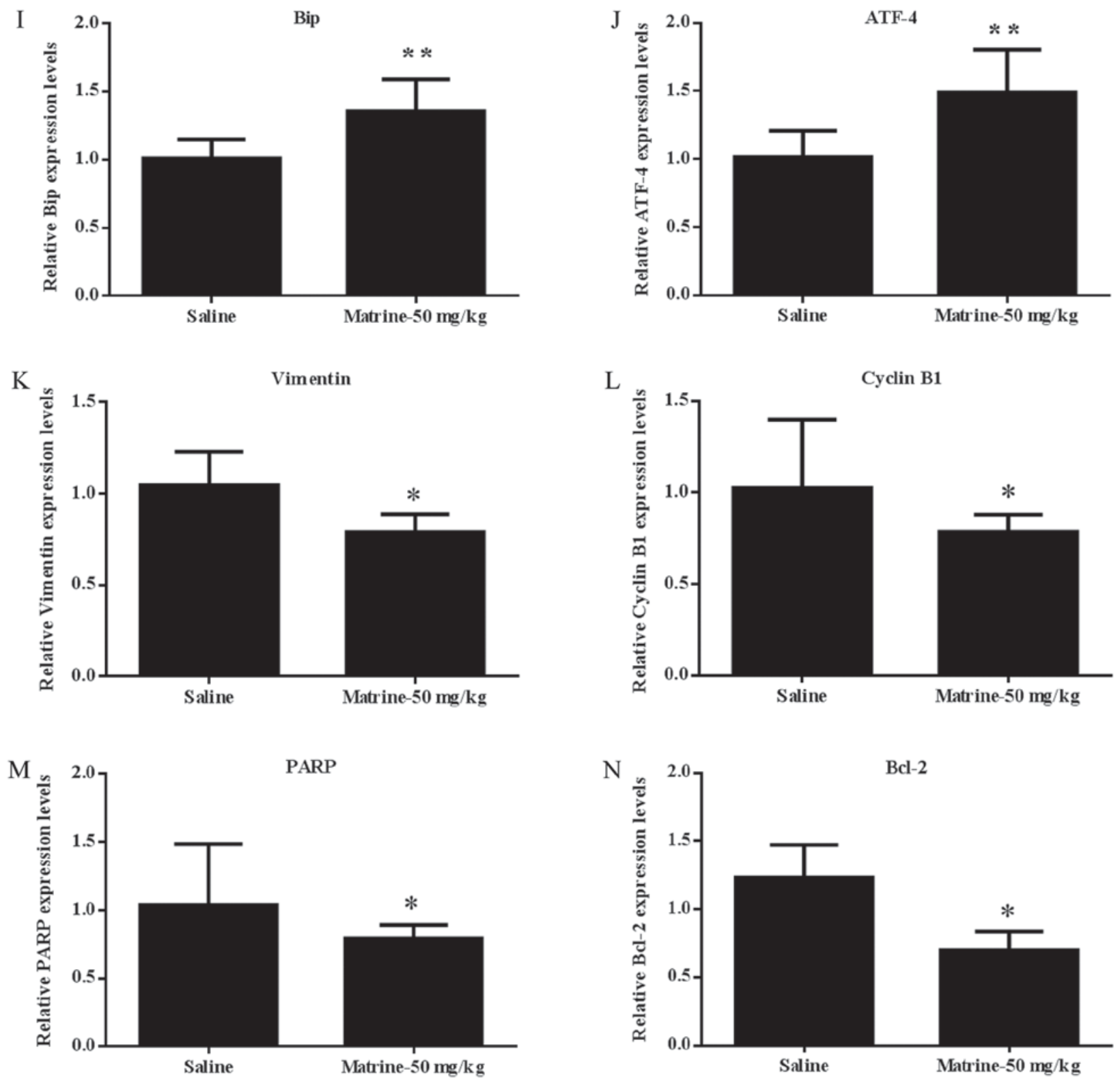

Figure 6. Continued. mRNA expression in the tumor extracts from three of the matrine-treated or saline-treated mice: (I) Bip; (J) ATF-4; (K) Vimentin; (L) CyclinB1; (M) PARP; and (N) Bcl-2. ${ }^{*} \mathrm{P}<0.05,{ }^{* *} \mathrm{P}<0.01$ compared with saline-treated mice. Matrine exerts its anticancer activity on human prostate cancer, in vitro and in vivo, via activation of the UPR/ER stress signaling cascade, inducing apoptosis and arresting the cell cycle at the G0/G1 phase, thus inhibiting cell proliferation by interrupting the Cyclin/CDK1 complex. ER, endoplasmic reticulum; UPR, unfolded protein response.

the expression of $\mathrm{Ki}-67$ in prostate cancer xenografts, which was indicated by stronger brown labeled nuclei. Furthermore, the cell cycle and growth associated protein Cyclin B1 was found to be down-regulated in the tumor tissues from matrine treated xenograft-bearing mice vs. saline-treated ones (Fig. 6L). These data further confirmed that matrine could also inhibit human prostate cancer cell proliferation in vivo.

Furthermore, up-regulated Bak (Fig. 6G) and PARP (Fig. $6 \mathrm{H}$ and $\mathrm{M}$ ), and down-regulated Bcl-2 (Fig. 6N), were found in the tumors of matrine-treated xenograft-bearing mice vs. the saline-treated mice, suggesting the activation of apoptosis in DU 145 tumors in vivo by matrine.

The schematic representation of the proposed therapeutic mechanisms of matrine in human prostate cancer is shown in Fig. 7.

\section{Discussion}

The lethality of prostate cancer is associated with its metastasis to other organs. EMT is a well-established biological procedure which converts epithelial cells to mesenchymal cells, and this has a significant role in both normal organ development and oncogenesis. EMT has attracted attention as a theoretical standard to elucidate progression and metastatic activity throughout cancer development. There is abundant proof that EMT-like status is the crucial process for metastasis and invasion in most epithelial cell source cancers, including prostate cancer, and has become an extremely active field of research (41). Therefore, using our knowledge of EMT-like status is potential future therapeutic avenue, and new compounds that can reverse EMT in prostate cancer cells are urgently needed. A number of potential anti-EMT compounds, including salinosporamide A 


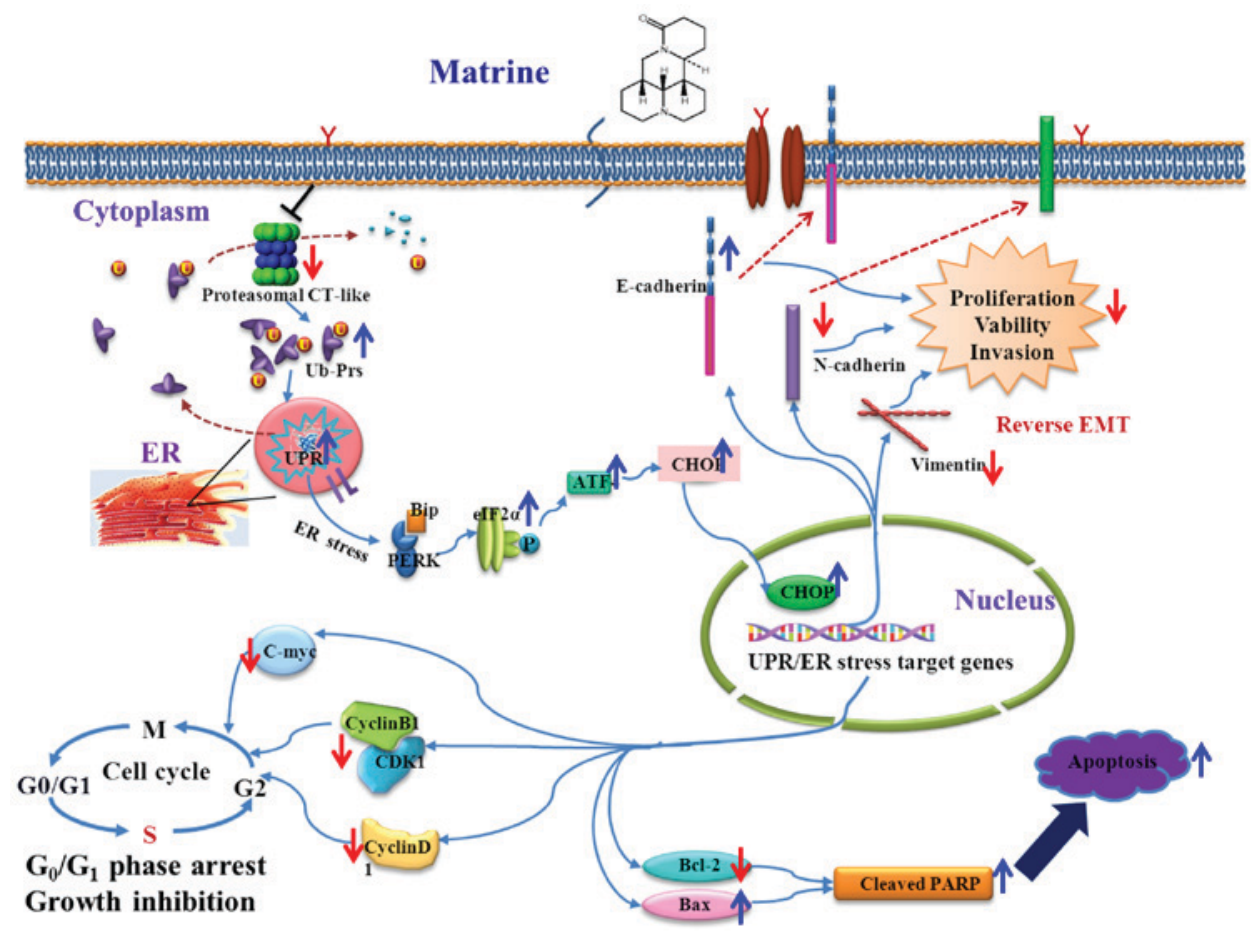

Figure 7. Schematic representation of the proposed therapeutic mechanisms of matrine in human prostate cancer.

(NPI-0052), the proteasome inhibitor, have been reported (42). Meanwhile, conventional chemotherapeutics cause side effects such as impaired renal function, gonadal dysfunction, hearing loss and myelosuppression (43).

Natural products and their derivatives have shown potential for cancer prevention and treatment because of their diverse structures, potential therapeutic effects and minimal side effects. Matrine is a principal active drug monomer in Sophora flavescens and has been used as an anti-cancer herbal medicine for hundreds of years in China with a broad range of pharmacological effects (22), without apparent side effects or toxicity. More up to date studies have found that matrine has effective anti-tumor activity, such as in multiple myeloma (44).

In this study, we assessed the effects of matrine on prostate cancer both in vitro and in vivo. The results showed that matrine inhibited tumor growth and Ki-67 expression in xenograft-bearing nude mice. Matrine also showed the ability to inhibit cell viability, arrest the cell cycle, induce apoptosis and suppress invasion and migration in prostate cancer, both in vivo and in vitro.

We conducted further experiments to explore the mechanism of matrine in suppressing prostate cancer. We confirmed that matrine inhibited intracellular proteasomal CT-like activity, which resulted in an accumulation of Ub-Prs in both prostate cancer cells and tumor tissues. We further found that matrine showed an anti-EMT effect in both DU145 and PC-3 prostate cancer cells, and the prostate tumor tissues of DU145 xenograft-bearing mice, as evidenced by up-regulated E-cadherin and down-regulated Vimentin and N-cadherin expression, which highlighted the anti-prostate cancer potential of matrine.

Unrestrained proliferation is an important feature of tumorigenesis, and the inhibition of proliferation leads to tumor cell growth arrest. The cell cycle is also important in regulating cell proliferation, cell division and cell growth. Cell cycle arrest might result in the an inhibition of cell growth or apoptotic cell death due to severe DNA damage (43).

We found that matrine caused cell cycle arrest at the $\mathrm{G}_{0} / \mathrm{G}_{1}$ phase by time dependently down-regulating Cyclin D1, Cyclin B1, c-Myc and CDK1 expression in DU145 and PC-3 prostate cancer cells, and also down-regulating Cyclin B1 in prostate cancer tumor tissues, suggesting that, both in vitro and in vivo, cell cycle arrest might be a mechanism underlying the anti-proliferative effect of matrine on prostate cancer. Our results further confirmed that matrine dose-dependently induced apoptosis and inhibited the survival of DU145 and PC-3 prostate cancer cells. Our results further demonstrated that matrine up-regulated BAX) and down-regulated Bcl-2 expression in both prostate cancer cells and tumor tissues. Therefore, our present study showed that matrine significantly inhibited proliferation, and also induced apoptosis in human prostate cancer in vitro and in vivo.

The ER is the center for protein folding and maturation. Impairment of the ER causes ER stress, which is activated by UPR and, in turn, alters cell activity and survival through regulation of protein synthesis, folding and degradation (45). UPR includes three key pathways: The PERK-eIF2 $\alpha$-ATF4-CHOP pathway, the IRE1-XBP1 pathway and the ATF6-chaperone pathway (46). The IRE1-XBP1 and ATF6-chaperone pathways mainly regulate ER chaperones, for instance GRP78 and p58IPK, thus promoting the ability of protein folding (47-50). Early activation of PERK decreases the protein translation rate by promoting eIF2 $\alpha$ phosphorylation, which allows the ER to recover from its stressed state. However, continued ER stress activates the downstream factors of the PERK pathway, such as pro-apoptotic gene $\mathrm{C} / \mathrm{EBP}$ homologous protein (CHOP), and causes apoptosis and cell death $(46,51,52)$. UPR can also potentiate the EMT of gastric cancer cells under situations 
of severe hypoxia (53). In current study, it was found that matrine time-dependently increased Bip, p-eIF2 $\alpha$, ATF4 and CHOP expression in DU145 and PC-3 prostate cancer cells, and increased Bip and ATF4 expression in prostate cancer tumor tissues. The increased expression of p-eIF2 $\alpha$ indicates the activation of PERK in UPR, which indirectly inactivates eIF2 and reduces mRNA translation (46). Meanwhile, p-eIF2 $\alpha$ activates transcription factor ATF4, and then stimulates its downstream transcription factor $\mathrm{CHOP}$, which is believed to regulate the genes involved in apoptosis (46).

Our study showed that matrine inhibited EMT, and induced cell cycle arrest and apoptosis both in human DU145 and PC-3 prostate cancer cells and DU145 xenograft tissues from DU145 xenograft-bearing mice, suggesting that matrine delays prostate cancer cell growth and induces apoptosis when persistent UPR/ER stress appeared. The anti-prostate cancer function of matrine might, at least partly, depend on the activation of UPR/ER stress.

In conclusion, we have shown that matrine, derived from Sophora flavescens, has potent and selective anti-prostate cancer activity by inhibiting proteasomal activity, reversing EMT, and inducing cell-cycle arrest and apoptosis by specific activating the UPR/ER stress signaling pathway, both in vitro and in vivo. Although further toxicological and pharmacological studies are required, our conclusion highlights the potential of matrine as a chemotherapeutic agent against prostate cancer and other UPR/ER stress activation-associated carcinomas.

\section{Acknowledgements}

Not applicable.

\section{Funding}

This study was supported by grants from the National Nature Science Foundation (grant nos. 81674006, 81603343, and 81102851); the Program for Innovative Research Team of Ministry of Science and Technology of China (grant no. 2015RA4002); the Xinglin Young Scholar, Xinglin Young Talent Program; and the Shanghai TCM Medical Center of Chronic Disease (grant no. 2017ZZ01010).

\section{Availability of data and materials}

The datasets used and/or analyzed during the current study are available from the corresponding author on reasonable request.

\section{Authors' contributions}

YY designed and coordinated the experiments; JC and SH carried out most of the experiments; QS analyzed the experimental results; WW and YL constructed and monitored the xenograft-bearing nude mouse model; WZ, YW and SL collected xenograft tissues; YY and YW wrote and edited the manuscript.

\section{Ethics approval and consent to participate}

The ethics approval was obtained from the Institutional Animal Care and Use Committee of Shanghai University of
TCM (ethics no. SZY2016004). All the animal experiments in this study were performed according to this approved ethics protocols.

\section{Consent for publication}

Not applicable.

\section{Competing interests}

The authors declare that they have no competing interests.

\section{References}

1. Xu S, Zhou W, Ge J and Zhang Z: Prostaglandin E2 receptor EP4 is involved in the cell growth and invasion of prostate cancer via the cAMP-PKA/PI3K-Akt signaling pathway. Mol Med Rep 17: 4702-4712, 2018

2. Zhu Y, Shao S, Pan H, Cheng Z and Rui X: MicroRNA-136 inhibits prostate cancer cell proliferation and invasion by directly targeting mitogen-activated protein kinase kinase 4. Mol Med Rep 17: 4803-4810, 2018.

3. Siegel R, Naishadham D and Jemal A: Cancer statistics, 2012. CA Cancer J Clin 62: 10-29, 2012.

4. Xie D, Gore C, Liu J, Pong RC, Mason R, Hao G, Long M, Kabbani W, Yu L, Zhang H, et al: Role of DAB2IP in modulating epithelial-to-mesenchymal transition and prostate cancer metastasis. Proc Natl Acad Sci USA 107: 2485-2490, 2010.

5. Chen X, Cheng H, Pan T, Liu Y, Su Y, Ren C, Huang D, Zha $X$ and Liang C: mTOR regulate EMT through RhoA and Racl pathway in prostate cancer. Mol Carcinog 54: 1086-1095, 2015.

6. Hanahan D and Weinberg RA: Hallmarks of cancer: The next generation. Cell 144: 646-674, 2011.

7. Thiery JP: Epithelial-mesenchymal transitions in tumour progression. Nat Rev Cancer 2: 442-454, 2002.

8. Thiery JP and Sleeman JP: Complex networks orchestrate epithelial-mesenchymal transitions. Nat Rev Mol Cell Biol 7: 131-142, 2006

9. Mani SA, Guo W, Liao MJ, Eaton EN, Ayyanan A, Zhou AY, Brooks M, Reinhard F, Zhang CC, Shipitsin M, et al: The epithelial-mesenchymal transition generates cells with properties of stem cells. Cell 133: 704-715, 2008.

10. Voutsadakis IA: The ubiquitin-proteasome system and signal transduction pathways regulating Epithelial Mesenchymal transition of cancer. J Biomed Sci 19: 67, 2012.

11. Adams J, Palombella VJ, Sausville EA, Johnson J, Destree A, Lazarus DD, Maas J, Pien CS, Prakash S and Elliott PJ: Proteasome inhibitors: A novel class of potent and effective antitumor agents. Cancer Res 59: 2615-2622, 1999.

12. Mani A and Gelmann EP: The ubiquitin-proteasome pathway and its role in cancer. J Clin Oncol 23: 4776-4789, 2005.

13. Wu WK, Cho CH, Lee CW, Wu K, Fan D, Yu J and Sung JJ: Proteasome inhibition: A new therapeutic strategy to cancer treatment. Cancer Lett 293: 15-22, 2010.

14. Huang T, Zhu Y, Fang X, Chi Y, Kitamura M and Yao J: Gap junctions sensitize cancer cells to proteasome inhibitor MG132-induced apoptosis. Cancer Sci 101: 713-721, 2010.

15. Seeger JM, Schmidt P, Brinkmann K, Hombach AA, Coutelle O, Zigrino P, Wagner-Stippich D, Mauch C, Abken H, Krönke M and Kashkar H: The proteasome inhibitor bortezomib sensitizes melanoma cells toward adoptive CTL attack. Cancer Res 70: 1825-1834, 2010.

16. Tagoug I, Jordheim LP, Herveau S, Matera EL, Huber AL, Chettab K, Manié S and Dumontet C: Therapeutic enhancement of ER stress by insulin-like growth factor I sensitizes myeloma cells to proteasomal inhibitors. Clin Cancer Res 19: 3556-3566, 2013.

17. Orlowski M and Wilk S: Catalytic activities of the $20 \mathrm{~S}$ proteasome, a multicatalytic proteinase complex. Arch Biochem Biophys 383: 1-16, 2000.

18. Arendt CS and Hochstrasser M: Identification of the yeast $20 \mathrm{~S}$ proteasome catalytic centers and subunit interactions required for active-site formation. Proc Natl Acad Sci USA 94: 7156-7161, 1997. 
19. Dick TP, Nussbaum AK, Deeg M, Heinemeyer W, Groll M, Schirle M, Keilholz W, Stevanović S, Wolf DH, Huber R, et al: Contribution of proteasomal beta-subunits to the cleavage of peptide substrates analyzed with yeast mutants. J Biol Chem 273: 25637-25646, 1998

20. Lopes UG, Erhardt P, Yao R and Cooper GM: p53-dependent induction of apoptosis by proteasome inhibitors. J Biol Chem 272: 12893-12896, 1997.

21. Shi G, Chen D, Zhai G, Chen MS, Cui QC, Zhou Q, He B, Dou QP and Jiang G: The proteasome is a molecular target of environmental toxic organotins. Environ Health Perspect 117: 379-386, 2009

22. Long Y, Lin XT, Zeng KL and Zhang L: Long Y, Lin XT, Zeng KL and Zhang L: Efficacy of intramuscular matrine in the treatment of chronic hepatitis B. Hepatobiliary Pancreat Dis Int 3: 69-72, 2004

23. Liu JY, Hu JH, Zhu QG, Li FQ, Wang J and Sun HJ: Effect of matrine on the expression of substance $\mathrm{P}$ receptor and inflammatory cytokines production in human skin keratinocytes and fibroblasts. Int Immunopharmacol 7: 816-823, 2007.

24. Yu P, Liu Q, Liu K, Yagasaki K, Wu E and Zhang G: Matrine suppresses breast cancer cell proliferation and invasion via VEGF-Akt-NF-kappaB signaling. Cytotechnology 59: 219-229, 2009.

25. Liu T, Song Y, Chen H, Pan S and Sun X: Matrine inhibits proliferation and induces apoptosis of pancreatic cancer cells in vitro and in vivo. Biol Pharm Bull 33: 1740-1745, 2010.

26. Nava MB, Rocco N, Catanuto G, Falco G, Capalbo E, Marano L, Bordoni D, Spano A and Scaperrotta G: Impact of contra-lateral breast reshaping on mammographic surveillance in women undergoing breast reconstruction following mastectomy for breast cancer. Breast 24: 434-439, 2015

27. Obeng EA, Carlson LM, Gutman DM, Harrington WJ Jr, Lee KP and Boise LH: Proteasome inhibitors induce a terminal unfolded protein response in multiple myeloma cells. Blood 107: 4907-4916, 2006.

28. Walter P and Ron D: The unfolded protein response: From stress pathway to homeostatic regulation. Science 334: 1081-1086, 2011.

29. Tabas I and Ron D: Integrating the mechanisms of apoptosis induced by endoplasmic reticulum stress. Nat Cell Biol 13 184-190, 2011

30. Hetz C, Chevet E and Harding HP: Targeting the unfolded protein response in disease. Nat Rev Drug Discov 12: 703-719, 2013.

31. Fan P, Griffith OL, Agboke FA, Anur P, Zou X, McDaniel RE Creswell K, Kim SH, Katzenellenbogen JA, Gray JW and Jordan VC: c-Src modulates estrogen-induced stress and apoptosis in estrogen-deprived breast cancer cells. Cancer Res 73 4510-4520, 2013

32. Huber AL, Lebeau J, Guillaumot P, Pétrilli V, Malek M, Chilloux J, Fauvet F, Payen L, Kfoury A, Renno T, et al: p58(IPK)-mediated attenuation of the proapoptotic PERK-CHOP pathway allows malignant progression upon low glucose. Mo Cell 49: 1049-1059, 2013

33. Jwa M and Chang P: PARP16 is a tail-anchored endoplasmic reticulum protein required for the PERK- and IRE1 $\alpha$-mediated unfolded protein response. Nat Cell Biol 14: 1223-1230, 2012.

34. McCullough KD, Martindale JL, Klotz LO, Aw TY and Holbrook NJ: Gadd153 sensitizes cells to endoplasmic reticulum stress by down-regulating $\mathrm{Bcl} 2$ and perturbing the cellular redox state. Mol Cell Biol 21: 1249-1259, 2001.

35. Gallerne C, Prola A and Lemaire C: Hsp90 inhibition by PU-H71 induces apoptosis through endoplasmic reticulum stress and mitochondrial pathway in cancer cells and overcomes the resistance conferred by Bcl-2. Biochim Biophys Acta 1833: 1356-1366, 2013

36. Chang J, Wang H, Wang X, Zhao Y, Zhao D, Wang C, Li Y, Yang Z, Lu S,Zeng Q, et al: Molecular mechanisms of Polyphyllin I-induced apoptosis and reversal of the epithelial-mesenchymal transition in human osteosarcoma cells. J Ethnopharmacol 170 : 117-127, 2015.
37. Shiota M, Bishop JL, Nip KM, Zardan A, Takeuchi A Cordonnier T, Beraldi E, Bazov J, Fazli L, Chi K, et al: Hsp27 regulates epithelial mesenchymal transition, metastasis, and circulating tumor cells in prostate cancer. Cancer Res 73: 3109-3119, 2013.

38. Dromparis P, Paulin R, Stenson TH, Haromy A, Sutendra G and Michelakis ED: Attenuating endoplasmic reticulum stress as a novel therapeutic strategy in pulmonary hypertension. Circulation 127: 115-125, 2013

39. Welch WJ and Brown CR: Influence of molecular and chemical chaperones on protein folding. Cell Stress Chaperones 1: 109-115, 1996.

40. Rastogi N and Mishra DP: Therapeutic targeting of cancer cell cycle using proteasome inhibitors. Cell Div 7: 26, 2012.

41. Nauseef JT and Henry MD: Epithelial-to-mesenchymal transition in prostate cancer: Paradigm or puzzle? Nat Rev Urol 8: 428-439, 2011.

42. King TE Jr, Pardo A and Selman M: Idiopathic pulmonary fibrosis. Lancet 378: 1949-1961, 2011.

43. van Rooij E and Olson EN: MicroRNA therapeutics for cardiovascular disease: opportunities and obstacles. Nat Rev Drug Discov 11: 860-872, 2012.

44. Nicolopoulou A, Cortina KS, Ilgaz H, Cates CB and de Sá AB Using a narrative- and play-based activity to promote low-income preschoolers' oral language, emergent literacy, and social competence. Early Child Res Q 31: 147-162, 2015.

45. Catov JM, Abatemarco D, Althouse A, Davis EM and Hubel C: Patterns of gestational weight gain related to fetal growth among women with overweight and obesity. Obesity (Silver Spring) 23: 1071-1078, 2015.

46. Keating SE, Hackett DA, Parker HM, O'Connor HT, Gerofi JA, Sainsbury A, Baker MK, Chuter VH, Caterson ID, George J and Johnson NA: Effect of aerobic exercise training dose on liver fat and visceral adiposity. J Hepatol 63: 174-182, 2015.

47. Mortensen DS, Fultz KE, Xu S, Xu W, Packard G, Khambatta G Gamez JC, Leisten J, Zhao J, Apuy J, et al: CC-223, a potent and selective inhibitor of mTOR kinase: In vitro and in vivo characterization. Mol Cancer Ther 14: 1295-1305, 2015.

48. Kruse CR, Nuutila K, Lee CC, Kiwanuka E, Singh M, Caterson EJ, Eriksson E and Sørensen JA: The external microenvironment of healing skin wounds. Wound Repair Regen 23: 456-464, 2015.

49. Woolcott OO, Richey JM, Kabir M, Chow RH, Iyer MS, Kirkman EL, Stefanovski D, Lottati M, Kim SP, Harrison LN, et al: High-fat diet-induced insulin resistance does not increase plasma anandamide levels or potentiate anandamide insulinotropic effect in isolated canine islets. PLoS One 10: e0123558, 2015.

50. Merlino A, Caterino M, Russo Krauss I and Vergara A: Missing gold atoms in lysozyme crystals used to grow gold nanoparticles. Nat Nanotechnol 10: 285, 2015.

51. Zimarino M, Ricci F, Romanello M, Di Nicola M, Corazzini A and De Caterina R: Complete myocardial revascularization confers a larger clinical benefit when performed with state-of-the-art techniques in high-risk patients with multivessel coronary artery disease: A meta-analysis of randomized and observational studies. Catheter Cardiovasc Interv 87: 3-12, 2016.

52. Yan H, Catania C and Bazan GC: Membrane-intercalating conjugated oligoelectrolytes: Impact on bioelectrochemical systems. Adv Mater 27: 2958-3973, 2015.

53. Niemczyk NA, Catov JM, Barinas-Mitchell E, McClure CK Roberts JM, Tepper PG and Sutton-Tyrrell K: Nulliparity is associated with less healthy markers of subclinical cardiovascular disease in young women with overweight and obesity. Obesity (Silver Spring) 23: 1085-1091, 2015.

This work is licensed under a Creative Commons Attribution-NonCommercial-NoDerivatives 4.0 International (CC BY-NC-ND 4.0) License. 